\title{
Characteristics of persons accused of intimate partner homicide amongst forensic psychiatric observations
}

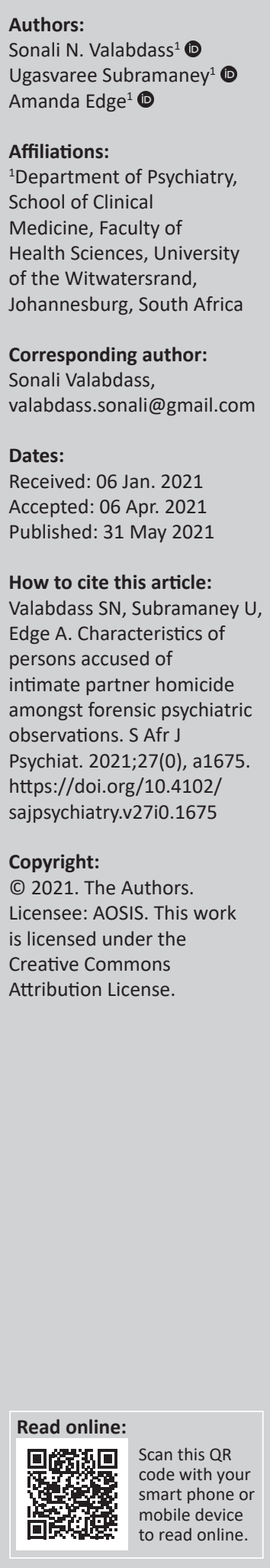

Background: Intimate partner homicide (IPH) is a global public health problem. One study conducted over 66 countries found that $13.5 \%$ of all homicides and $38.6 \%$ of female homicides were committed by an intimate partner. In South Africa, there were no published studies that examine alleged perpetrators of IPH that were referred for forensic psychiatric observation.

Aim: To describe the profile of accused persons referred for forensic psychiatric observation for a charge of murder or attempted murder of their intimate partners. Certain characteristics were further examined according to the psychiatric observation outcomes.

Setting: The study was conducted at Sterkfontein Hospital, a forensic psychiatric hospital in Gauteng, South Africa.

Methods: A retrospective record review of accused persons referred for forensic psychiatric observation for a charge of murder or attempted murder of their intimate partners was conducted. The period of the review was 19 years. The definition of intimate partners included current or former spouses and partners, same-sex partners and rejected suitors.

Results: One hundred and sixty-three files, which included forensic psychiatric reports, were reviewed. The findings related to the profile of accused persons and offence characteristics indicated that: (1) history of violent behaviour is prevalent; (2) homicides mostly occur in private homes; (3) knives and firearms are most often used; (4) infidelity, separation and jealousy are common motives; (5) psychotic disorders, personality disorders and substance use disorders feature prominently. A total of $88 \%$ of the sample were found fit to stand trial and $82 \%$ were found criminally responsible. Factors significantly associated with being found fit to stand trial and criminally responsible following the forensic psychiatric observation were: male gender, having received a tertiary education, employment prior to the offence, earning a salary of more than R10 000, having no previous psychiatric or medical illness, a positive forensic history, previous intimate partner violence (IPV) perpetration, indicating a motive for the homicide, having no psychiatric illness at the time of the offence which would impact fitness to stand trial and criminal responsibility.

Factors significantly associated with being found not fit to stand trial and not criminally responsible following the forensic psychiatric observation were: female gender, having received a primary education, unemployment prior to the offence, having a previous psychiatric or medical illness, no forensic history, no previous IPV perpetration, not indicating a motive for the homicide, having a psychiatric illness at the time of the offence which would impact fitness to stand trial and criminal responsibility.

Conclusion: The characteristics highlighted in this study can contribute to the development of risk assessment tools which can be used to identify likely perpetrators of IPH. Other interventions, for example controlling access to knives and firearms, reducing substance abuse and improving mental health services, are also important in the prevention of IPH.

Keywords: IPV; IPH; IPH characteristics; IPH perpetrators; IPH perpetrator characteristics; forensic psychiatric observation; IPH risk factors.

\section{Introduction}

Intimate partner homicide (IPH), defined as 'the intentional killing of one's current or former partner ${ }^{\prime}, 1$ is considered the most extreme form of intimate partner violence (IPV). Such homicides may involve spouses, ex-spouses, current or former partners, or partners of same-sex relationships and include both male and female victims. ${ }^{1,2}$ Fatal IPV can be best understood as 'an extension of 
the IPV phenomenon rather than within the scope of general homicide'. ${ }^{3}$

A global study conducted over 66 countries found that $13.5 \%$ of all homicides and $38.6 \%$ of female homicides were committed by an intimate partner. ${ }^{4}$ A national study of female homicides in South Africa (SA) found that, in 1999 and 2009, approximately $50 \%$ of victims were murdered by an intimate partner. ${ }^{5,6}$ This highlights that IPH is a global public health problem that needs to be addressed. In order to curb incidences of IPH, understanding the profiles of these accused persons might assist with identification of potential perpetrators.

Some literature on IPH considers the high prevalence of mental illness amongst perpetrators. ${ }^{1,2,7,8,9}$ In a study that examined 153 alleged perpetrators referred for forensic psychiatric observation for a charge of murder in Illinois, Missouri, Indiana, Colorado or Arizona, $45.8 \%$ had a psychiatric diagnosis. ${ }^{2}$ Another study, that was a consecutive case series of all convicted IPH perpetrators in England and Wales between 1997 and 2008, found a 32\% lifetime prevalence rate of mental illness. ${ }^{7}$ In a national study conducted in Portugal, $14.3 \%$ of alleged IPH perpetrators who were subjected to a forensic psychiatric observation, were found not criminally responsible because of mental illness. ${ }^{3}$ An Italian study showed similar results $(12.6 \%) .{ }^{10}$ In SA, a study that examined alleged homicide perpetrators (of which $44 \%$ were alleged IPH perpetrators) referred for forensic psychiatric observation to Weskoppies Psychiatric Hospital, found that $56 \%$ had a psychiatric diagnosis at the time of the incident that impacted on criminal responsibility. ${ }^{11}$

Significant gaps exist in the current literature with regard to the profile of accused persons and offence characteristics in cases of IPH referred for forensic psychiatric observation. Despite much research on the general population that commits IPH; few studies have addressed accused persons who are referred for forensic psychiatric observation.

Forensic psychiatric observations are conducted when the court has reason to believe accused persons may be suffering from a mental illness or intellectual disability which may be impacting on the individual's fitness to stand trial (the ability to comprehend court proceedings) and/or criminal responsibility (the ability to appreciate the wrongfulness of an act and to act in accordance with such an appreciation). ${ }^{12}$

Within the South African context, such accused persons are referred by the court to a psychiatric hospital for a forensic psychiatric observation in terms of sections 77, 78 and 79 of the Criminal Procedure Act (CPA) 51 of 1977, as amended. ${ }^{13,14}$ Accused persons undergoing forensic psychiatric observation are referred to as observandi. During the psychiatric observation period, the accused person may undergo several assessments by members of the multi-disciplinary team (psychiatrists, clinical psychologists, occupational therapists, social workers and nurses). These assessments always include psychiatric interviews and physical examinations and may include laboratory tests, psychological assessments, occupational assessments and social worker reports. A final report is completed by the psychiatrist(s) for the court, which comments on the accused person's diagnosis (if any), their fitness to stand trial and criminal responsibility.

For those who are found not fit to stand trial and/or not criminally responsible, for a serious or major offence (for example murder, attempted murder, sexual assault or assault with intent to cause grievous bodily harm [assault GBH]), the accused is usually admitted to the forensic unit as a state patient in terms of section 42 of the Mental Health Care Act 17 of 2002 for care, treatment and rehabilitation. ${ }^{15}$

As there is no specific charge of IPH or IPV in SA, this research study focussed on murder and attempted murder of intimate partners in the context of forensic psycho-legal assessments in Johannesburg, SA. Attempted murder was included in this study as the authors wanted to investigate the profile of accused persons who had shown intent to commit murder of their intimate partners regardless of whether the act was successful or not. The authors are of the opinion that the profile of accused persons charged with IPH is more associated with the intent to commit murder rather than with the outcome of the act, and that this warranted the inclusion of attempted murder cases in this study. Persons accused of assault GBH against their intimate partner were not included in this study as the authors could not be confident that these accused persons had demonstrated intent to commit murder and thus the authors believed that their profile would be markedly different to those that were accused of murder or attempted murder of their intimate partners.

\section{Aims}

The primary aim of this study was to describe the sociodemographic, clinical and forensic profile of accused persons referred for forensic psychiatric observation, under the CPA, to Sterkfontein Hospital for a charge of murder or attempted murder of an intimate partner. The study also sought to examine offence characteristics and to describe the outcomes of the forensic psychiatric observation. The accused and offence characteristics, as well as diagnosis, were further examined according to the categories of psychiatric observation outcomes, that is, whether accused persons were found to be either fit to stand trial or not fit to stand trial and criminally responsible or not criminally responsible.

\section{Methods \\ Study design and setting}

This was a retrospective record review of accused persons referred for forensic psychiatric observation to Sterkfontein Hospital with a charge of murder or attempted murder during a 19-year period, from 01 January 2000 to 31 December 2018.

The study was conducted at the forensic section of Sterkfontein Hospital, a tertiary psychiatric hospital providing both general and forensic psychiatric services, situated in Gauteng, SA. 


\section{Study population}

The sample included records of all adult (age $\geq 18$ years) males and females referred as observandi from 01 January 2000 to 31 December 2018 for the charges of murder or attempted murder of their intimate partners. The definition of intimate partners included current or former spouses and partners, same-sex partners and rejected suitors. The definition of IPH includes those homicides that were successful and those that were unsuccessful, that is, files included in this study were of those accused persons referred for forensic psychiatric observation with a charge of murder or attempted murder of their intimate partner.

\section{Data collection}

Case files for IPH were identified via the forensic unit admission register, psychiatric reports and clinical records. Data collection took place between January 2019 and June 2019. Data were collected from psychiatric reports and clinical records. Data were captured using a data collection sheet which included socio-demographic, clinical, forensic, offence and psychiatric observation factors.

\section{Data analysis}

All statistical analyses were conducted using Python (Scipy.stats module; https://docs.scipy.org/doc/scipy/ reference/stats). All tests were two-tailed probability values. Categorical variables were summarised using frequency tables. Fitness to stand trial and criminal responsibility classifications were compared against accused characteristics, offence characteristics and diagnosis. Pearson's chi-squared test was used to determine statistical significance. A $p$-value of $<0.05$ was considered significant.

\section{Ethical considerations}

The protocol was approved by the University of the Witwatersrand's Human Research Ethics Committee (clearance certificate number: M180530). Permission to use Sterkfontein Hospital as the site for the research was granted by the hospital's research committee. All data were collected by the primary investigator who was responsible for ensuring the anonymity, confidentiality and security of data obtained.

\section{Results}

\section{Profile of accused persons}

A total of 145 male and 18 female accused persons were included in this study (Table 1). Of these, $44 \%$ were unemployed. Thirty-three accused persons had a previous psychiatric illness (18 described a mood disorder, 14 a psychotic disorder and 1 a personality disorder [PD]). Fiftyseven accused persons were found to have one or more medical illnesses and 108 accused persons admitted to using one or more substances. Ethanol and cannabis were the most commonly reported substances used. Ten per cent of accused persons reported that they had experienced childhood trauma. Thirty-seven per cent reported a
TABLE 1: Socio-demographic, clinical and forensic profile of accused persons.

\begin{tabular}{|c|c|c|}
\hline Characteristics & $N$ & $\%$ \\
\hline \multicolumn{3}{|l|}{ Age } \\
\hline 18 to 30 & 50 & 31 \\
\hline 31 to 40 & 52 & 32 \\
\hline Over 40 & 61 & 37 \\
\hline \multicolumn{3}{|l|}{ Gender } \\
\hline Female & 18 & 11 \\
\hline Male & 145 & 89 \\
\hline \multicolumn{3}{|l|}{ Marital status (at the time of the offence) } \\
\hline Single & 73 & 45 \\
\hline Married & 59 & 36 \\
\hline Separated & 19 & 12 \\
\hline Divorced & 12 & 7 \\
\hline \multicolumn{3}{|l|}{ Cohabiting } \\
\hline No & 79 & 48 \\
\hline Yes & 84 & 52 \\
\hline \multicolumn{3}{|l|}{ Schooling } \\
\hline Mainstream & 156 & 96 \\
\hline Special & 3 & 2 \\
\hline No formal education & 4 & 2 \\
\hline \multicolumn{3}{|l|}{ Highest level of education } \\
\hline No formal education & 4 & 2 \\
\hline Primary education & 20 & 12 \\
\hline Secondary education & 91 & 56 \\
\hline Tertiary education & 48 & 29 \\
\hline \multicolumn{3}{|l|}{ Employment status } \\
\hline Employed & 91 & 56 \\
\hline Unemployed not on a disability grant & 65 & 40 \\
\hline Unemployed on a disability grant & 7 & 4 \\
\hline \multicolumn{3}{|l|}{ Salary } \\
\hline Ro - R5000 & 4 & 2 \\
\hline R5000 - R10 000 & 28 & 17 \\
\hline$>$ R10 000 & 59 & 36 \\
\hline \multicolumn{3}{|l|}{ Previous psychiatric illness } \\
\hline No & 130 & 80 \\
\hline Yes & 33 & 20 \\
\hline \multicolumn{3}{|l|}{ Previous psychiatric diagnosis (DSM-IV-TR) } \\
\hline Antisocial personality disorder & 1 & 1 \\
\hline Schizophrenia & 10 & 6 \\
\hline Schizoaffective disorder & 1 & 1 \\
\hline Psychotic disorder due to a general medical condition & 2 & 1 \\
\hline Substance-induced psychotic disorder & 1 & 1 \\
\hline Major depressive disorder & 13 & 8 \\
\hline Mood disorder due to a general medical condition & 2 & 1 \\
\hline Bipolar I disorder & 2 & 1 \\
\hline Bipolar II disorder & 1 & 1 \\
\hline \multicolumn{3}{|l|}{ Medical illness } \\
\hline No & 106 & 65 \\
\hline Yes & 57 & 35 \\
\hline \multicolumn{3}{|l|}{ Medical diagnosis } \\
\hline Previous head trauma & 29 & 18 \\
\hline Epilepsy & 21 & 13 \\
\hline Diabetes mellitus & 10 & 6 \\
\hline HIV & 6 & 4 \\
\hline \multicolumn{3}{|l|}{ History of substance use } \\
\hline No & 55 & 34 \\
\hline Yes & 108 & 66 \\
\hline \multicolumn{3}{|l|}{ Substance } \\
\hline Ethanol & 79 & 48 \\
\hline Cannabis & 46 & 28 \\
\hline Nicotine & 27 & 17 \\
\hline Stimulants & 11 & 7 \\
\hline
\end{tabular}

Table 1 continues on the next page $\rightarrow$ 
TABLE 1 (Continues...): Socio-demographic, clinical and forensic profile of accused persons.

\begin{tabular}{|c|c|c|}
\hline Characteristics & $N$ & $\%$ \\
\hline \multicolumn{3}{|l|}{ Childhood trauma } \\
\hline No & 146 & 90 \\
\hline Yes & 17 & 10 \\
\hline \multicolumn{3}{|l|}{ Nature of childhood trauma } \\
\hline Physical and/or sexual abuse & 10 & 6 \\
\hline Witnessed domestic violence & 5 & 3 \\
\hline Both of the above & 1 & 1 \\
\hline Other & 1 & 1 \\
\hline \multicolumn{3}{|l|}{ Forensic history } \\
\hline No & 103 & 63 \\
\hline Yes & 60 & 37 \\
\hline \multicolumn{3}{|l|}{ Previous charge } \\
\hline Murder & 4 & 2 \\
\hline Attempted murder & 5 & 3 \\
\hline Assault with intent to cause grievous bodily harm & 26 & 16 \\
\hline Domestic violence & 2 & 1 \\
\hline Protection order contravention & 10 & 6 \\
\hline Robbery & 20 & 12 \\
\hline Malicious damage to property & 1 & 1 \\
\hline \multicolumn{3}{|l|}{ History of violent behaviour } \\
\hline No & 86 & 53 \\
\hline Yes & 77 & 47 \\
\hline \multicolumn{3}{|l|}{ Perpetrator of domestic violence } \\
\hline Indicated - no & 34 & 21 \\
\hline Indicated - yes & 42 & 26 \\
\hline Not indicated & 87 & 53 \\
\hline \multicolumn{3}{|l|}{ Victim of domestic violence } \\
\hline No & 156 & 96 \\
\hline Yes & 7 & 4 \\
\hline
\end{tabular}

DSM-IV-TR, Diagnostic and Statistical Manual of Mental Disorders, 4th Edition, Text Revision

TABLE 2: Offence characteristics.

\begin{tabular}{|c|c|c|}
\hline Characteristics & $N$ & $\%$ \\
\hline \multicolumn{3}{|l|}{ Nature of the charge } \\
\hline Murder & 124 & 76 \\
\hline Attempted murder & 39 & 24 \\
\hline \multicolumn{3}{|c|}{ Relationship to the accused } \\
\hline Spouse & 75 & 46 \\
\hline Partner & 65 & 40 \\
\hline Ex-partner & 10 & 6 \\
\hline Ex-spouse & 5 & 3 \\
\hline Fiancé & 4 & 2 \\
\hline Rejected suitor & 4 & 2 \\
\hline \multicolumn{3}{|l|}{ Killing method } \\
\hline Stabbing & 76 & 47 \\
\hline Gunshot & 43 & 26 \\
\hline Strangulation & 16 & 10 \\
\hline Blunt trauma & 13 & 8 \\
\hline Arson & 4 & 2 \\
\hline Poisoning & 1 & 1 \\
\hline Other & 6 & 4 \\
\hline Mixed & 4 & 2 \\
\hline \multicolumn{3}{|l|}{ Murder weapon } \\
\hline Knife & 70 & 43 \\
\hline Firearm & 43 & 26 \\
\hline Bodily force & 14 & 9 \\
\hline Fire & 4 & 2 \\
\hline Poison & 1 & 1 \\
\hline Other & 27 & 17 \\
\hline Mixed & 4 & 2 \\
\hline
\end{tabular}

Table 2 continues in the next column $\rightarrow$
TABLE 2: (Continues...): Offence characteristics.

\begin{tabular}{lcc}
\hline Characteristics & $\boldsymbol{N}$ & $\%$ \\
\hline Setting & 128 & 79 \\
Residence & 14 & 9 \\
Street & 21 & 13 \\
Other & & \\
Substance use at the time of offence & 112 & 69 \\
No & 51 & 31 \\
Yes & & \\
Motive & 115 & 71 \\
Indicated & 48 & 29 \\
Not indicated & & \\
Nature of the motive & 51 & 31 \\
Rage & 36 & 22 \\
Infidelity & 35 & 21 \\
Separation & 21 & 13 \\
Jealousy & 11 & 7 \\
Self-defence & 3 & 2 \\
Possessiveness & 1 & 1 \\
Financial benefit & 1 & 1 \\
Retaliation & & \\
\hline & & \\
\hline
\end{tabular}

TABLE 3: Psychiatric observation outcomes.

\begin{tabular}{lcc}
\hline Characteristics & N & $\%$ \\
\hline Psychiatric diagnosis & & \\
Not present & 82 & 50 \\
Present & 81 & 50 \\
Psychiatric diagnosis (DSM-IV-TR) & & \\
Antisocial personality disorder & 20 & 12 \\
Borderline personality disorder & 3 & 2 \\
Narcissistic personality disorder & 1 & 1 \\
Dependent personality disorder & 1 & 1 \\
Substance use disorder & 29 & 18 \\
Schizophrenia & 11 & 7 \\
Schizoaffective disorder & 1 & 1 \\
Psychotic disorder not otherwise specified & 2 & 1 \\
Psychotic disorder due to a general medical condition & 9 & 6 \\
Substance-induced psychotic disorder & 1 & 1 \\
Major depressive disorder & 12 & 7 \\
Mood disorder due to a general medical condition & 2 & 1 \\
Mental retardation & 2 & 1 \\
Dementia & 134 \\
Fitness to stand trial & 29 & 82 \\
Fit & 5 & 3 \\
Not fit & 20 & 12 \\
Criminal responsibility & & \\
Not criminally responsible & & 18 \\
\hline DSM-IV-TR, Diasponsible & & \\
\hline
\end{tabular}

DSM-IV-TR, Diagnostic and Statistical Manual of Mental Disorders, 4th Edition, Text Revision.

forensic history, with a few accused persons reporting more than one charge. Of the sample, $26 \%$ were previous perpetrators of IPV. Previous IPV perpetration was confirmed by the accused person and/or collateral reports.

\section{Offence characteristics}

The vast majority of the victims were the current spouse or partner of the accused (Table 2). Stabbing (using a knife) was the most common killing method, followed by gunshot. The majority of offences occurred at a residence. 
Sixty-nine per cent of accused persons reported to not have used a substance at the time of the offence. Considerably more accused persons indicated a motive. Of those that indicated a motive, rage, infidelity and separation were the most common.

\section{Psychiatric observation outcomes}

The Diagnostic and Statistical Manual of Mental Disorders, 4th Edition, Text Revision (DSM-IV-TR) classification system was used in this study. Half of the sample were found to have a psychiatric diagnosis (Table 3). Of these, some were found to have more than one diagnosis. Overall, $18 \%$ had a substance use disorder(SUD), 15\% had a PD, 15\% had a psychotic disorder, $9 \%$ had a mood disorder, $3 \%$ had dementia and $1 \%$ had mental retardation. Considerably more observandi were found fit to stand trial than not fit to stand trial and considerably more accused persons were found criminally responsible than not criminally responsible.

\section{Fitness to stand trial and criminal responsibility}

Gender was found to be a significant predictor for fitness to stand trial and criminal responsibility (Table 4 ).
Males were more likely to be found fit and criminally responsible whereas females were more likely to be found not fit and not criminally responsible.

The level of education completed also had a significant association with fitness to stand trial and criminal responsibility. Accused persons who achieved lower levels of education were more likely to be found not fit and not criminally responsible. Those who had obtained a tertiary education were more likely to be found fit and criminally responsible.

Employment status and salary were significantly associated with fitness to stand trial and criminal responsibility. Accused persons who were employed were more likely to be found fit and criminally responsible. Accused persons who earned more than R10 000 were more likely to be found fit and criminally responsible.

Previous psychiatric illness was found to be a significant predictor for fitness to stand trial and criminal responsibility. Accused persons with a previous psychiatric

TABLE 4: Accused and offence characteristics and diagnosis according to the categories of psychiatric observation outcomes with $p$ values.

\begin{tabular}{|c|c|c|c|c|c|}
\hline \multirow[t]{2}{*}{ Characteristics } & \multirow[t]{2}{*}{$N$} & \multicolumn{2}{|c|}{ Fitness to stand trial } & \multicolumn{2}{|c|}{ Criminal responsibility } \\
\hline & & Not fit (\%) & $p$ & Not responsible (\%) & $p$ \\
\hline Age & & & 0.14 & & 0.09 \\
\hline 18 to 30 & 50 & 12 & & 14 & \\
\hline 31 to 40 & 52 & 6 & & 12 & \\
\hline Over 40 & 61 & 18 & & 26 & \\
\hline Gender & & & $<0.01 *$ & & $<0.01 *$ \\
\hline Male & 145 & 8 & & 13 & \\
\hline Marital status (at the time of the offence) & & & 0.75 & & 0.53 \\
\hline Single & 73 & 14 & & 15 & \\
\hline Married & 59 & 12 & & 22 & \\
\hline Separated & 19 & 5 & & 11 & \\
\hline Divorced & 12 & 17 & & 25 & \\
\hline Highest level of education & & & $0.02 *$ & & $0.01 *$ \\
\hline Primary education & 20 & 30 & & 35 & \\
\hline Secondary education & 91 & 12 & & 19 & \\
\hline Tertiary education & 48 & 4 & & 6 & \\
\hline Employment status & & & $<0.01 *$ & & $0.02 *$ \\
\hline Employed & 91 & 4 & & 11 & \\
\hline Unemployed not on a disability grant & 65 & 20 & & 25 & \\
\hline Unemployed on a disability grant & 7 & 43 & & 43 & \\
\hline Salary & & & $<0.01^{*}$ & & $0.03 *$ \\
\hline R0 - R5000 & 4 & 0 & & 25 & \\
\hline R5000 - R10 000 & 28 & 14 & & 18 & \\
\hline$>\mathrm{R} 10000$ & 59 & 0 & & 7 & \\
\hline Previous psychiatric illness & & & $<0.01 *$ & & $0.02 *$ \\
\hline No & 130 & 8 & & 14 & \\
\hline Yes & 33 & 30 & & 33 & \\
\hline Psychotic disorder & 14 & 64 & & 71 & \\
\hline Mood disorder & 18 & 6 & & 6 & \\
\hline Medical illness & & & $0.01 *$ & & $<0.01 *$ \\
\hline No & 106 & 7 & & 10 & \\
\hline Yes & 57 & 23 & & 32 & \\
\hline
\end{tabular}


TABLE 4 (Continues...): Accused and offence characteristics and diagnosis according to the categories of psychiatric observation outcomes with $p$ values.

\begin{tabular}{|c|c|c|c|c|c|}
\hline \multirow[t]{2}{*}{ Characteristics } & \multirow[t]{2}{*}{$N$} & \multicolumn{2}{|c|}{ Fitness to stand trial } & \multicolumn{2}{|c|}{ Criminal responsibility } \\
\hline & & Not fit (\%) & $p$ & Not responsible $(\%)$ & $p$ \\
\hline \multicolumn{6}{|l|}{ Medical diagnosis } \\
\hline Previous head trauma & 29 & 24 & 0.07 & 31 & 0.07 \\
\hline Epilepsy & 21 & 24 & 0.17 & 38 & $0.02 *$ \\
\hline HIV & 6 & 33 & 0.33 & 50 & 0.12 \\
\hline History of substance use & & & 0.38 & & 0.11 \\
\hline Yes & 108 & 10 & & 14 & \\
\hline Childhood trauma & & & 0.75 & & 0.73 \\
\hline No & 146 & 12 & & 18 & \\
\hline Yes & 17 & 12 & & 12 & \\
\hline Nature of childhood trauma & & & 0.82 & & 0.81 \\
\hline Physical and/or sexual abuse & 10 & 20 & & 20 & \\
\hline Both of the above & 1 & 0 & & 0 & \\
\hline Other & 1 & 0 & & 0 & \\
\hline Forensic history & & & 0.06 & & $0.03 *$ \\
\hline No & 103 & 17 & & 23 & \\
\hline Yes & 60 & 5 & & 8 & \\
\hline History of violent behaviour & & & 0.06 & & 0.19 \\
\hline No & 86 & 17 & & 22 & \\
\hline Yes & 77 & 6 & & 13 & \\
\hline Perpetrator of domestic violence & & & $<0.01 *$ & & $<0.01 *$ \\
\hline Indicated - no & 34 & 32 & & 47 & \\
\hline Indicated-yes & 42 & 0 & & 5 & \\
\hline Not indicated & 87 & 10 & & 13 & \\
\hline Victim of domestic violence & & & 0.05 & & 0.21 \\
\hline Substance use at the time of offence & & & 0.70 & & 0.80 \\
\hline No & 112 & 13 & & 19 & \\
\hline Yes & 51 & 10 & & 16 & \\
\hline Motive & & & $0.02 *$ & & $<0.01 *$ \\
\hline Indicated & 115 & 8 & & 11 & \\
\hline Not indicated & 48 & 23 & & 33 & \\
\hline Psychiatric diagnosis & & & $<0.01 *$ & & $<0.01 *$ \\
\hline Not present & 82 & 0 & & 1 & \\
\hline Present & 81 & 25 & & 35 & \\
\hline \multicolumn{6}{|l|}{ Psychiatric diagnosis } \\
\hline Personality disorder & 25 & 0 & 0.09 & 4 & 0.09 \\
\hline Substance use disorder & 29 & 10 & 0.97 & 17 & 0.86 \\
\hline Psychotic disorder & 24 & 67 & $<0.01 *$ & 83 & $<0.01 *$ \\
\hline Mood disorder & 14 & 7 & 0.85 & 21 & 0.99 \\
\hline Mental retardation & 2 & 0 & 0.58 & 0 & 0.79 \\
\hline Dementia & 5 & 60 & $0.01 *$ & 80 & $<0.01 *$ \\
\hline
\end{tabular}

*, statistically significant.

illness, particularly a psychotic disorder, were more likely to be found not fit and not criminally responsible compared to those without a previous psychiatric diagnosis who were more likely to be found fit and criminally responsible. Those diagnosed with a previous mood disorder were more likely to be found fit and criminally responsible.

Those with a medical illness were more likely to be found not fit and not criminally responsible compared to those without a medical illness who were more likely to be found fit and criminally responsible. Accused persons with a diagnosis of epilepsy were more likely to be found not criminally responsible.

Forensic history was significantly associated with criminal responsibility but not fitness to stand trial. Accused persons with a forensic history were more likely to be found criminally responsible compared to those with no forensic history, who were more likely to be found not criminally responsible.

A history of IPV perpetration and reporting a motive were significantly associated with fitness to stand trial and 
criminal responsibility. Accused persons with a history of committing previous IPV were more likely to be found fit and criminally responsible compared to those accused persons who were not previous IPV perpetrators, who were more likely to be found not fit and not criminally responsible. Accused persons who indicated a motive were more likely to be found fit and criminally responsible.

The presence of a psychiatric diagnosis at the time of the offence was significantly associated with fitness to stand trial and criminal responsibility. Having psychopathology in keeping with a psychiatric diagnosis, particularly a psychotic disorder or dementia, at the time of the offence, made it more likely for accused persons to be found not fit and not criminally responsible.

\section{Discussion}

This study concurred with the findings in the literature that perpetrators of IPH are predominantly men. $2,7,8,9,16,17,18$

Some studies indicate that approximately half of male perpetrators of IPH had not completed high school and the majority of female offenders have limited educational achievements. ${ }^{19,20}$

This is contrary to our findings which showed that $14 \%$ of the sample had not completed secondary education.

A high percentage of accused persons (44\%) were unemployed at the time of the offence, a finding consistent with those of most studies. $5,7,19,21,22,23$ The finding that there is an association between employment status and fitness to stand trial corresponds with the findings of another South African study. ${ }^{24}$

In a study that examined characteristics of IPH perpetrators, mental illness was rarely diagnosed before the incident, ${ }^{17}$ contrary to a Dutch study which showed that $59 \%$ of offenders had previous contact with psychiatric services. ${ }^{23}$ Our study showed that $20 \%$ of the sample had been diagnosed with a mental illness prior to the offence.

Few studies have addressed the presence of medical illnesses amongst IPH perpetrators. Bourget and Gagné reported that $64 \%$ of women and $43 \%$ of men in their sample had chronic illnesses. ${ }^{8}$ In Hanlon and colleagues' study, $11 \%$ of the sample had epilepsy, ${ }^{2}$ which is similar to our results of $13 \%$ having epilepsy. The importance of epilepsy in this context warrants further study, particularly preictal, ictal and postictal psychopathology.

Literature suggests childhood trauma plays a significant role in the risk of IPH perpetration..$^{23,25,26}$ Childhood trauma can include physical and/or sexual abuse or witnessing violence between parents. Putkonen and colleagues found that $61 \%$ of female homicide offenders and $39 \%$ of male homicide offenders had experienced physical violence in their family. ${ }^{21}$ However, only $10 \%$ of our sample reported childhood trauma. Given the important role that adverse childhood events play in the risk of IPH perpetration, the low incidence is likely because of either under-reporting by the observandi or a recording omission by the original assessors, who may have neglected to enquire about childhood trauma at the time.

In this study, $37 \%$ of alleged perpetrators had a forensic history and $47 \%$ had a history of violent behaviour. These findings were similar to those in the literature which shows that approximately $25 \%-50 \%$ of all male IPH perpetrators have been imprisoned for a previous brutal crime. ${ }^{1,2,3,9,23}$ Female IPH offenders show less previous criminality compared to their male counterparts. ${ }^{8,19,21}$

In SA, domestic violence is quoted as the main causal factor that results in IPHs. ${ }^{20}$ It is very uncommon for a fatal act of violence against a partner to be the first occurrence of IPV. ${ }^{3,5,10,23,25}$ In Leth's study, 50\% of victims had experienced previous IPV. ${ }^{18}$ Whilst spousal homicides often occur in the setting of IPV, it is important to consider this in the context of gender. Literature consistently indicates that:

$[M]$ ale perpetrators are likely to have subjected their partner to previous IPV, and are more likely to murder them following an escalation of violence, whereas women are more likely to kill in self-defence, as an extreme reaction to their victimisation, and/or to protect children. ${ }^{9,18}$

This is further supported by the findings from two national studies conducted from 2003 to 2015 in North America. ${ }^{17,27}$ In our study, however, only $26 \%$ of the sample reported being previous perpetrators of IPV. It is possible that this percentage is significantly under-reported as the records mainly consisted of information obtained from the alleged perpetrators' account and accused persons may have withheld or denied certain information in order to protect their reputation and avoid incrimination. Additionally, no victim characteristics were examined in this study, such as forensic autopsies or police reports, which may have provided more objective information.

Our study found a similar proportion of victims that were killed by their spouses (46\%), in comparison to those that were killed by a non-marital partner $(42 \%)$. This is contradictory to the literature which shows that IPH occurs more frequently within common-law relationships than those in marital relationships..$^{6,8,25}$

Alleged perpetrators killed their intimate partners most often in private residences, using a knife or firearm, which is supported by previous research. $2,3,6,8,9,17,18,19,20,25,27$

Despite the high incidences of substance use in cases of non-fatal IPV, and a study indicating that a significant relationship exists between male perpetrators' alcohol abuse and violence against intimate female partners, ${ }^{28}$ some studies reveal that most IPH perpetrators did not use alcohol or drugs at the time of the homicide, in spite of their normally high substance abuse rates. ${ }^{1,2,8}$ This was similar to our 
findings which showed that $69 \%$ of the sample reported not using substances at the time of the offence. This could be because of under-reporting in a forensic environment.

Women rarely kill an intimate partner after the couple has separated but men are at greater risk of perpetrating IPH when separation of the relationship has occurred or is imminent. ${ }^{13,9,18,23,25,26}$ A Portuguese study found that most women were murdered by ex-partners within a year of separation, highlighting that a significant risk persists even after the couple's separation. ${ }^{3}$ Jealousy and infidelity are common motives for men to commit IPH., $3,17,18,22,25$ Our study was consistent with the literature which showed rage, infidelity and separation as the most common motives for murder.

Our study showed that $50 \%$ of the sample were found to have a psychiatric diagnosis at the time of the offence.

These results, however, must be interpreted with caution as PDs and SUDs were included in this category and these disorders alone do not impact fitness to stand trial and criminal responsibility. It is important to note, however, that PDs and SUDs may have an impact on IPV perpetration at large. Following forensic psychiatric observation (for IPH), studies indicate that psychotic disorders are most common, followed by mood disorders and anxiety disorders. ${ }^{2,11,23}$

Our study found similar results: $15 \%$ had a psychotic disorder and $9 \%$ a mood disorder. Oram and colleagues, however, found contradictory results in that affective disorders were most common. ${ }^{7}$ Our findings resembled the literature in that there is a high prevalence of PDs in this population, particularly cluster B pathology (borderline, narcissistic, histrionic and antisocial)., 2,10,23,25,26 Research indicates that approximately $10 \%-20 \%$ of IPH perpetrators have a lifetime primary diagnosis of substance dependence. ${ }^{3,23}$ Our study showed similar findings with $18 \%$ of accused persons being found to have an SUD.

Multiple studies revealed that $14 \%-20 \%$ of alleged IPH perpetrators, referred for forensic psychiatric observation, were deemed not criminally responsible because of the presence of a psychiatric disorder. , $7,19,21$ Our study showed similar results $(18 \%)$. This reinforces the need to refer accused persons of IPH for forensic psychiatric observation.

\section{Limitations}

The study's retrospective nature is a limitation, in that data may not always be complete and information gathered from others' notes also has the potential to be inaccurate. Another limitation is that accused persons with PDs or SUDs were included amongst those individuals who were found to have 'severe' psychiatric illness whose fitness to stand trial and criminal responsibility were impacted. Additionally, these are alleged IPH perpetrators (who are still awaiting trial) so one has to be wary of drawing conclusions about actual convicted perpetrators. Assault GBH of an intimate partner was not included in the analyses, and the authors acknowledge the severe consequences of pervasive assault GBH over time which may be a precursor to attempted murder and murder. This warrants further study.

\section{Conclusion}

This is the first South African published study examining IPH within the context of forensic psychiatric observations. The primary aim of this study was to describe the sociodemographic, clinical and forensic profile of accused persons referred for forensic psychiatric observation, under the CPA, for a charge of IPH. The study also sought to examine offence characteristics and to describe the outcomes of the forensic psychiatric observation. Theaccused and offencecharacteristics, as well as diagnosis, were further examined according to the categories of psychiatric observation outcomes, that is, fitness to stand trial and criminal responsibility.

The main findings of this study were: (1) history of violent behaviour is prevalent; (2) homicides mostly occur in private homes; (3) knives and firearms are most often used; (4) infidelity, separation and jealousy are common motives; (5) psychotic disorders, PDs and SUDs feature prominently. Childhood trauma and previous IPV perpetration did not feature prominently. It is essential that an understanding of childhood trauma and IPV perpetration in the context of IPH is pursued, especially in developing countries, so that data can be compared globally. Furthermore, given the small number of alleged female perpetrators, we were not able to explore differences by gender. Future research is needed to examine gender differences amongst IPH perpetrators in SA.

From this study, the 'typical' fit and criminally responsible alleged perpetrator of IPH is a male who would have attained a tertiary education, would be employed prior to the offence and earning more than R10 000 a month. He would have no previous mental illness or medical illness but would have a positive forensic history. He would have a history of IPV perpetration and would indicate a motive for the homicide. Following the forensic psychiatric observation, he would not be found to have a psychiatric illness that impacted fitness to stand trial and criminal responsibility but may have a diagnosis of PD and/or SUD.

The 'typical' not fit and not criminally responsible alleged perpetrator of IPH is a female who would have attained only a primary education. She would be unemployed prior to the offence and have a history of previous mental illness. She may have a medical illness but would have no forensic history. She would not have a history of IPV perpetration and would not indicate a motive for the homicide. Following the forensic psychiatric observation, she would be found to have a psychiatric illness that impacted fitness to stand trial and criminal responsibility such as a psychotic disorder or dementia.

The study highlights multiple risk factors in those who are accused of IPH and are sent for forensic psychiatric observation. This information is valuable in that it can assist 
in preventing IPH, through the development of risk assessment tools which can be used for identification of likely perpetrators. Other interventions such as monitoring access to weapons such as knives and firearms, interventions to reduce alcohol and substance abuse and improving mental health services should all be addressed in order to reduce the incidence of IPH.

\section{Acknowledgements}

The authors acknowledge Devesh Naidu (Senior Quantitative Analyst) for his assistance with the statistical analysis.

\section{Competing interests}

The authors declare that they have no financial or personal relationships that may have inappropriately influenced them in writing this article.

\section{Authors' contributions}

S.N.V. was the principal author and U.S. and A.E. supervised the project. S.N.V., U.S. and A.E. collectively designed the study. S.N.V. collected and analysed the data and drafted the article. All authors critically revised the article and gave final approval of the version to be published.

\section{Funding information}

This research received no specific grant from any funding agency in the public, commercial or not-for-profit sectors.

\section{Data availability}

The authors confirm that the data supporting the findings of this study are available within the article.

\section{Disclaimer}

The views and opinions expressed in this article are those of the authors and do not necessarily reflect the official policy or position of any affiliated agency of the authors.

\section{References}

1. Kivisto AJ. Male perpetrators of intimate partner homicide: A review and proposed typology. J Am Acad Psychiatry Law. 2015;43(3):300-312.

2. Hanlon RE, Brook M, Demery JA, Cunningham MD. Domestic homicide: Neuropsychological profiles of murderers who kill family members and intimate partners. J Forensic Sci. 2016;61(1):163-170. https://doi.org/10.1111/1556-4029.12908

3. Pereira AR, Vieira DN, Magalhães T. Fatal intimate partner violence against women in Portugal: A forensic medical national study. J Forensic Leg Med 2013;20(8):1099-1107. https://doi.org/10.1016/j.jflm.2013.09.015

4. Stöckl H, Devries K, Rotstein A, et al. The global prevalence of intimate partner homicide: A systematic review. Lancet. 2013;382(9895):859-865. https://doi. org/10.1016/S0140-6736(13)61030-2
5. Abrahams N, Mathews S, Martin LJ, Lombard C, Jewkes R. Intimate partner femicide in South Africa in 1999 and 2009. PLoS Med. 2013:10(4):e1001412. https://doi.org/10.1371/journal.pmed.1001412

6. Abrahams N, Jewkes R, Martin LJ, Mathews S, Vetten L, Lombard C. Mortality of women from intimate partner violence in South Africa: A national epidemiological study. Violence Vict. 2009;24(4):546-556. https://doi.org/10.1891/08866708.24.4.546

7. Oram S, Flynn SM, Shaw J, Appleby L, Howard LM. Mental illness and domestic homicide: A population-based descriptive study. Psychiatr Serv. 2013;64(10):1006-1011. https://doi.org/10.1176/appi.ps.201200484

8. Bourget D, Gagné P. Women who kill their mates. Behav Sci Law. 2012;30(5):598-614. https://doi.org/10.1002/bsl.2033

9. Sabri B, Campbell JC, Dabby FC. Gender differences in intimate partner homicides among ethnic subgroups of Asians. Violence Against Women. 2016;22(4):432-453. https://doi.org/10.1177/1077801215604743

10. Carabellese F, Tamma M, La Tegola D, Candelli C, Catanesi R. Women victims of violent partners: The Italian situation amid culture and psychopathology. J Forensic Sci. 2014;59(2):533-539. https://doi.org/10.1111/15564029.12347

11. Sussman $P$, Kotze $C$. Psychiatric features in perpetrators of homicide-unsuccessful suicide at Weskoppies Hospital in a 5 -year period. S Afr J Psychiatr. 2013;19(1):15-18. https://doi.org/10.4102/sajpsychiatry.v19i1.384

12. Kaliski S. Psycholegal assessment in South Africa. Cape Town: Oxford University Press; 2006

13. South Africa. Criminal Procedure Act No. 51 of 1977. Government Gazette, 6 May 1977, Vol. 143, No. 5532

14. South Africa. Criminal Procedure Amendment Act No. 4 of 2017. Government Gazette, 29 June 2017, Vol. 624, No. 40946.

15. South Africa. Mental Health Care Act No. 17 of 2002. Government Gazette, 6 November 2002, Vol. 449, No. 24024

16. Eriksson L, Mazerolle P. A general strain theory of intimate partner homicide. Aggress Violent Behav. 2013;18(5):462-470. https://doi.org/10.1016/j. avb.2013.07.002

17. Velopulos CG, Carmichael H, Zakrison TL, Crandall M. Comparison of male and female victims of intimate partner homicide and bidirectionality - An analysis of the national violent death reporting system. J Trauma Acute Care Surg. 2019;87(2):331-336. https://doi.org/10.1097/TA.0000000000002276

18. Leth PM. Intimate partner homicide. Forensic Sci Med Pathol. 2009;5(3):199-203. https://doi.org/10.1007/s12024-009-9097-5

19. Hellen F, Lange-Asschenfeldt C, Ritz-Timme S, Verhülsdonk S, Hartung B. How could she? Psychosocial analysis of ten homicide cases committed by women. $J$ Forensic Leg Med. 2015;36(1):25-31. https://doi.org/10.1016/j.jflm.2015.08.007

20. Hesselink A, Dastile P. A criminological assessment on South African women who murdered their intimate male partners. J Psychol Afr. 2015;25(4):335-344. https://doi.org/10.1002/cbm.782

21. Putkonen $\mathrm{H}$, Weizmann-Henelius $\mathrm{G}$, Lindberg $\mathrm{N}$, Rovamo T, Häkkänen-nyholm $\mathrm{H}$. Gender differences in homicide offenders' criminal career, substance abuse and mental health care. A nationwide register-based study of Finnish homicide offenders 1995-2004. Crim Behav Ment Health. 2011:21(1):51-62. https://doi. org/10.1002/cbm.782

22. Mathews S, Abrahams N, Jewkes R, Martin LJ, Lombard C, Vetten L. Intimate femicide-suicide in South Africa: a cross-sectional study. Bull World Health Organ. 2008;86(7):552-558. https://doi.org/10.2471/BLT.07.043786

23. Liem M, Koenraadt F. Familicide: A comparison with spousal and child homicide by mentally disordered perpetrators. Crim Behav Ment Health. 2008;18(5):306-318. https://doi.org/10.1002/cbm.710

24. Houidi A, Paruk S, Sartorius B. Forensic psychiatric assessment process and outcome in state patients in KwaZulu-Natal, South Africa. S Afr J Psychiatry. 2018;24(0):a1142. https://doi.org/10.4102/sajpsychiatry.v24i0.1142

25. Aldridge M, Browne K. Perpetrators of spousal homicide: A review. Trauma Violence Abuse. 2003;4(3):265-276. https://doi.org/10.1177/152483800 3004003005

26. Elisha E, Idisis $Y$, Timor U, Addad M. Typology of intimate partner homicide: Personal, interpersonal, and environmental characteristics of men who murdered their female intimate partner. Int J Offender Ther Comp Criminol. 2010;54(4):494-516. https://doi.org/10.1177/0306624X09338379

27. Rizo CF, Mennicke A, Deinse TV. Characteristics and factors associated with intimate partner violence-related homicide post-release from jail or prison. Interpers Violence. 2019;1-28.

28. Sharps PW, Campbell J, Campbell D, Gary F, Webster D. The role of alcohol use in intimate partner femicide. Am J Addict. 2001;10(2):122-135. https://doi. org/10.1080/105504901750227787 